\title{
ESTUDO DA EXTRAÇÃO DE ÓLEO DO CAROÇO DE ALGODÃO POR SOLVENTE ALTERNATIVO
}

\author{
S. M. SILVA ${ }^{1}$, L. F. O. MAIA ${ }^{2}$ e S. M. Damasceno ${ }^{3}$ \\ ${ }^{1}$ Acadêmico da Faculdade de Ciência e Tecnologia de Montes Claros - FACIT. \\ ${ }^{2}$ Mestre em Química e professor Faculdade de Ciência e Tecnologia de Montes Claros - FACIT \\ ${ }^{3}$ Mestra em Química Orgânica e professora do Instituto de Ciência e Tecnologia (ICT) da \\ Universidade Federal dos Vales de Jequitinhonha e Mucuri - UFVJM. \\ E-mail para contato: snard_mendonca@yahoo.com.br
}

\begin{abstract}
RESUMO - O óleo de algodão é utilizado em muitos processos industriais e para consumo humano. Quando bruto apresenta uma coloração bastante escura devido à presença de uma biomolécula importante para planta chamada gossipol, que se liga fortemente às demais matérias graxas do óleo, dificultando e onerando o processo de refino. A extração com teores reduzidos desse composto maximiza o valor de mercado do óleo e de seus derivados. Foram utilizados os solventes acetato de etila (AE), ciclohexano $(\mathrm{CH})$, etanol (ET) e suas misturas nas proporções $80 \% \mathrm{AE}: 20 \% \mathrm{CH}, 60 \% \mathrm{AE}: 40 \%$ $\mathrm{CH}, 80 \% \mathrm{AE}: 20 \% \mathrm{ET}$ e $60 \% \mathrm{AE}: 40 \% \mathrm{ET}$; para o estudo e os resultados foram comparados ao obtido com o solvente convencional utilizado na extração de oleaginosas, o hexano (HE). Baseado nos teores de gossipol e rendimento, os solventes e misturas propostas não conseguiram alcançar resultados equiparáveis ao HE. Entretanto, alguns resultados sinalizam uma possibilidade de trabalho com dois solventes: o $\mathrm{CH}$ e ET.
\end{abstract}

\section{INTRODUÇÃO}

O algodoeiro é "uma planta ereta, anual ou perene, dotada de raiz principal cônica, pivotante, profunda e com pequeno número de raízes secundárias grossas e superficiais” (Meneses, 2007, p. 21) pertencente ao gênero Gossypium (tribo Gossypieae, família Malvacea, ordem Malvales) de grande serventia à humanidade desde tempos remotos. Do algodoeiro originam-se várias matérias-primas para a indústria. Além da fibra de algodão, que é vastamente utilizada, ainda se obtêm muitos materiais de sua semente de grande aplicabilidade, como o óleo e a torta. Entre outras aplicações, citase o uso do óleo na produção de biodiesel. Para tal, o mesmo deve apresentar condições mínimas de qualidade para ser processado pelas tecnologias existentes. Essa qualidade é bastante influenciada pela forma como é feita a extração e o processo de refino. Das técnicas utilizadas na extração, destacam-se duas, que podem ser combinadas para a obtenção de maior rendimento operacional, que são a extração tradicional por prensagem ou por extração com solvente. Tradicionalmente, visando melhorar o rendimento do processo, a semente passa por aquecimento/cozimento após laminação em "pellets"(Rodrigues, 2011). 
A extração com solvente é baseada na dissolução da matéria graxa contida nos "pellets" com um solvente não polar, normalmente a hexana que contém uma mistura de isômeros do hexano, sendo este seu componente principal (Kemper, 2005; Rodrigues, 2011). Também conhecido como processo em micela, "a extração de óleos vegetais por solvente envolvem mecanismos de lixiviação, lavagem, difusão e diálise", segundo Williams (2005), Becker (1978), Karnofsky (1949), apud. Rodrigues (2011, p. 28). Segundo Kemper (2005), sob uma perspectiva microscópica, o óleo é produzido na célula vegetal e armazenado em "corpos oleosos" de formato esférico, que o isola do resto do citoplasma. Durante a extração, o solvente precisa difundir para dentro das células até tais "corpos". Depois, a micela concentrada com o material oleaginoso é novamente difundido para o meio extracelular, atravessando as paredes celulares por efeito do próprio gradiente de concentração até atingir o equilíbrio, posto que o tempo para atingir essa condição varia de oleaginosa para oleaginosa.

As folhas, sementes e caule do algodoeiro (Gossypium sp.) possuem glândulas intracelulares que secretam um pigmento sesquiterpenoide denominado gossipol, que pode ser extraído junto com o óleo. Sua estrutura é mostrada na figura 1. Esse composto, segundo Kenar (2006) e Pesce (2008), é um complexo polifenólico que faz parte do sistema de defesa da planta contra pragas, além disso, possui cor amarelada, é antioxidante e antipolimerizante. A quantidade desse composto varia de acordo com a espécie. O gossipol pode ser encontrado livre ou combinado às proteínas presentes no endosperma da semente. Quando extraído, o processamento promove a ruptura de membranas das glândulas e permite a mistura do gossipol com o óleo e com a torta. Embora grande parte do pigmento se incorpore a massa proteica, a porção que se liga ao óleo faz com que esse adquira uma coloração de vermelho a negro, removida apenas na etapa de refino (O'Brien et al., 2005). Neste trabalho objetivou-se alcançar opções de melhorar o desempenho dos sistemas testando o uso de solventes alternativos e avaliando sua eficácia na extração de óleo sem contaminantes como o gossipol.

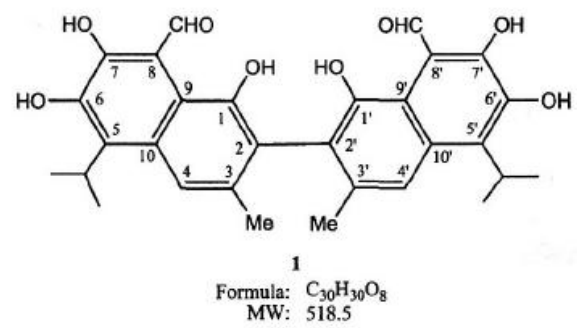

Figura 1 - Estrutura molecular do gossipol

Fonte: Kenar (2006, p. 270)

\section{MATERIAIS E MÉTODOS}

Nesta pesquisa foi utilizada semente de algodão delintada, decortificada e moída, gentilmente cedida pela Agroforte ${ }^{\circledR}$. 


\subsection{Procedimento}

Como forma de caracterização inicial realizou-se uma avaliação da umidade do material, por gravimetria. Pesou-se em um cadinho tarado, determinada massa da amostra que foi submetida a ciclos na estufa de temperatura de $110^{\circ} \mathrm{C}$ por $30 \mathrm{~min}$., até que se alcançasse peso constante. A redução da massa representa a massa de água perdida.

2.1.1 Extração com material cru: As sementes moídas e decortificadas foram pesadas e inseridas no extrator entre dois anéis de algodão que impedem que o material seja escoado junto com a micela sifonada no braço lateral do extrator, ou que venha a ser flotado e escoado pelo canal de vapor de solvente fresco, em caso de descontrole nos fluxos. A quantidade de amostra foi acondicionada de forma que o leito tivesse aproximadamente $10 \mathrm{~cm}$, e massa entre $60 \mathrm{~g}$ e $80 \mathrm{~g}$. A regulagem dos fluxos se deu por meio do aquecimento da manta aquecedora que vaporizava o solvente e da temperatura da água de resfriamento que circulava no condensador. O ponto de operação se deu quando havia um fluxo constante descendente de micela para o balão de fundo redondo pelo canal de sifonação, e se procedeu até que não houvesse mais evidência de extração, ou seja, quando o solvente permanecesse límpido após atravessar o leito. Essa estrutura caracteriza o sistema como extração de leito inundado. O óleo obtido após os ensaios foi devidamente acondicionado, pesado e separado para caracterização. Os ensaios extrativos foram realizado de acordo com as informações contida na tabela 1. O material sólido que deixou o extrator foi transferido com cautela para que não houvesse perda de massa para um béquer compatível e foi levado a aquecimento de $110^{\circ} \mathrm{C}$ por no mínimo $2 \mathrm{~h}$.

Tabela 1 - Composição da alimentação de solvente no extrator com amostra crua.

\begin{tabular}{ccccc}
\hline TESTES & \multicolumn{4}{c}{ SOLVENTES } \\
\cline { 2 - 5 } & Hexano $^{1}$ & Acetato de Etila & Ciclohexano $^{3}$ & Etanol $^{4}$ \\
\hline 1 & $100 \%$ & - & - & - \\
(Grupo Controle & & $100 \%$ & - & - \\
2 & - & - & $100 \%$ & - \\
3 & - & - & - & $100 \%$ \\
4 & - & $80 \%$ & $20 \%$ & - \\
5 & - & $60 \%$ & $40 \%$ & - \\
6 & - & $80 \%$ & - & $20 \%$ \\
7 & - & $60 \%$ & - & $40 \%$ \\
\hline
\end{tabular}

Fonte: Autoria própria

Legenda:1-Isofar; 2-Neon Química; 3-Vetec; 4-FMaia

2.1.2 Extração com material pré-tratado: Com o intuito de avaliar a extração com diferentes preparos da carga do extrator, utilizou-se um sistema de peneiramento, dotado de agitação com as peneiras Tyler de 8,16,100,150 mesh, para conduzir com a fração julgada conveniente uma corrida análoga às realizadas com amostra bruta, utilizando com o solvente acetato de etila. 


\section{9 a 22 de outubro de 2014 \\ Florianópolis/SC}

2.1.3 Avaliação analítica do óleo e determinação de gossipol total em óleo - AOCS Ca 13-56: Avaliou-se primeiramente o rendimento da extração tomando como base, o óleo recuperado na destilação da micela em comparação a toda a massa de amostra presente e de possível solvência. Uma alíquota de cada extração foi tratada com 3-amino-1-propanol (Sigma Aldrich) em dimetilformamida (Vetec) a $50^{\circ} \mathrm{C}$ por $30 \mathrm{~min}$. formando um complexo diaminopropanol. A mistura foi então reagida com anilina (Vetec) e submetida às mesmas condições. O dianilinogossipol formado foi filtrado, diluído em solução de Hexano (Isofar)/Ácido Acético (Vetec) 1:1 e levado ao espectrofotômetro UV/VIS (Spekol/Analytic Jena), este absorve na região de $440 \mathrm{~nm}$, e foi então quantificado, frente a um ensaio em branco, por meio de interpolação em curva de analítica construída pelos valores de absorbância lidos para os padrões de concentrações conhecidas de gossipol (Sigma Aldrich).

\section{RESULTADOS E DISCUSSÃO}

Por avaliação de aspecto do material, visualizou-se uma grande quantidade de cascas misturadas ao endosperma triturado. Essa fração do material é considerada indesejável uma vez que ocupa lugar no extrator de partículas que teriam potencial extração, ou seja, que possuam esferossomos de óleos em suas células. Utilizando o sistema de peneiramento pode-se obter o perfil granulométrico médio da amostra com as peneiras (tabela 2). As frações que acumularam a maior parte de material foram as duas peneiras intermediárias. Os sólidos com tamanho superior a 2,38 mm e menores que 0,106 mm, são praticamente desprezíveis, se comparados com as demais frações. É conveniente ressaltar que a fração com diâmetro entre 2,38 e $1 \mathrm{~mm}$ se exprime em grande parte pelas cascas e de fragmentos do grão com volume relativamente maior. Segundo literatura, para extração por solvente, é comum que se obtenha uma espessura menor para facilitar a transferência de massa da micela através do material (Rodrigues, 2011). Portanto, tal fração (peneira 16) foi inferida como de possível minimizante no rendimento da extração, motivo pelo qual foi feita uma extração com a fase retida na peneira inferior (peneira 100). Optou-se por não utilizar as porções mais finas que essa, pois em sistemas industriais, particulados muito finos impedem a percolação eficiente do leito de oleaginosa pelo solvente.

Avaliou-se também a umidade retida nessa massa antes da extração por gravimetria simples com cadinho em estufa. Após medição a peso constante, em duplicata, verificou-se que a amostra continha adsorvida em sua superfície cerca de 8,3\% em peso de umidade. Segundo Kemper (2005), em geral, condiciona-se o material com aparelhos de secagem até se alcançar cerca de $3 \%$ em peso de água. Optou-se por não aquecer a carga nesse trabalho, pois não havia no momento forma de avaliar a homogeneidade desse aquecimento, uma vez que, Kemper (2005) ainda comenta, que um calor muito acentuado pode ajudar na fixação de cor no óleo. Essa umidade adsorvida pode ser um fator minimizante no processo extrativo quando tratado com solventes muito apolares. Seguindo a metodologia proposta de extração, ao montar o sistema de modo a formar um leito fixo inundado (em flooding), observou-se que era possível controlar o sistema com as temperaturas de aquecimento do solvente e de resfriamento do condensador, evidenciado pela manutenção da quantidade do solvente ao término do processo. A grande maioria dos óleos vegetais possui coloração amarelada devido aos componentes minoritários presentes neles, portanto, é oportuno se estender o processo extrativo até 
que a micela, que deixa o leito se apresente incolor. As bateladas de extração levaram em média 3 a 4 h para chegarem até o ponto que se julgou conveniente parar, ou seja, incolor ou de coloração estável. Em todos os casos, rapidamente se obteve uma micela escura após todo o leito ter lido "inundado" com solvente. Visualmente pode-se dizer que a maior parte da extração ocorreu nos primeiros $20 \mathrm{~min}$. de procedimento, reduzindo gradualmente a coloração.

A tabela 2 compila o rendimento calculado, com base na massa de óleo recuperado e os teores de gossipol total, preconizado na AOCS Ca 13-56, das amostras citadas na tabela 1, que foram renomeadas com os códigos utilizados no momento da prática, em ordem cronológica de preparo. Foi feita também, como supramencionado, uma extração com a porção com granulometria entre 1 e 0,150 $\mathrm{mm}$, utilizando como solvente o acetato de etila, avaliando assim o pré-tratamento da carga antes do processo. Os dados tratados referentes ao rendimento das amostras estão evidenciados também no gráfico da figura 2. Pode-se verificar que o hexano possui um rendimento de $29,37 \%$, semelhante ao obtido para o acetato de etila puro e mistura AE (60 \%): ET(40\%) com valores de 31,19 e 37,39, respectivamente. Um fato interessante é o das micelas que apresentam ciclohexano em sua composição (AE (80 \%): $\mathrm{CH}(20 \%), \mathrm{AE}(60 \%): \mathrm{CH}(40 \%), \mathrm{CH}(100 \%))$ apresentam um valor baixo de rendimento. Ressalta-se que essas são as amostras com caráter apolar mais acentuado, excetuando o grupo controle. A extração com etanol puro e AE (80\%):ET(20\%) apresentou um rendimento superior ao do grupo controle. O etanol é um solvente relatado na literatura como formador de azeótropo e de alto calor de vaporização quando comparado com o hexano (JOHSON; LUSAS, 1983), dificultando muito o processo de destilação, isso pode indicar um falso poder extrativo do etanol, uma vez que a medida foi feita com base no peso do óleo recuperado.

Tabela 2 - Avaliação prática da extração

\begin{tabular}{cccc}
\hline \multirow{2}{*}{ Amostras } & Descrição & Rendimento & Teor de gossipol total \\
\cline { 3 - 4 } & & \% & mg/kg \\
\hline A & AE $(100 \%)$ & 31,19 & 1651,2 \\
B & AE $(60 \%):$ ET $(40 \%)$ & 37,39 & 1842,3 \\
C & AE $(80 \%):$ CH $(20 \%)$ & 17,38 & 1470,5 \\
D & AE $(60 \%):$ CH(40\%) & 14,27 & 1420,6 \\
E & CH $(100 \%)$ & 14,50 & 426,4 \\
F & AE (80 \%): ET(20\%) & 46,53 & 1465,3 \\
G & ET (100\%) & 52,25 & 816,8 \\
H & HX $(100 \%)$ & 29,37 & 399,3 \\
I & AEp $(100 \%)$ & 58,49 & 1303,3 \\
\hline
\end{tabular}

Legenda:AE: Acetato de Etila, AEp, Acetato de Etila (fração de finos), CH: Ciclohexano, ET: Etanol, HX: Hexano (grupo controle)

Fonte: $\mathrm{O}$ autor 


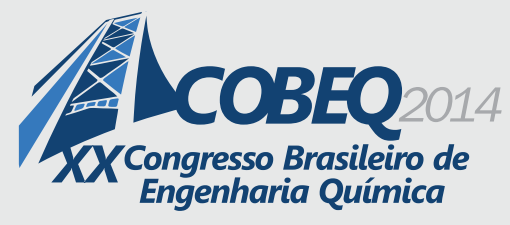

19 a 22 de outubro de 2014

Florianópolis/SC

Em alguns casos, como nas extrações que tinham como componente o etanol, a coloração final não foi incolor, mesmo após encontrado o equilíbrio. Tal efeito pode ser explicado pela maior polaridade do etanol em relação aos demais solventes, não conseguindo dissolver completamente o material apolar presente. Esse fato é refutado pelo aspecto do rafinado, que foi bem mais amarelado que os demais. Visualmente os demais rafinados e posteriores tortas secas se apresentavam bastante semelhantes. Outra forma de avaliar o óleo obtido foi por meio do ensaio colorimétrico em espectrofotometria na região do espectro visível. Os padrões foram preparados com concentrações conhecidas, a partir de um padrão de Gossipol, tratado na presença e ausência de anilina. Uma relação linearizada foi levantada entre a absorbância lida e a massa do padrão presente em cada solução. Consoante ao preconizado na norma, a reta possui coeficiente de correlação 0,9997, o que mostra que as condições analíticas oferecem base para uma interpolação fidedigna das absorbâncias lidas nas amostras. Essas foram submetidas ao mesmo tratamento sistemático dado aos padrões da curva analítica. Respeitando todos os intervalos de tempo requeridos, as absorbâncias foram lidas, corrigidas pelos valores sem anilina, e então interpoladas. Os resultados obtidos para os teores de gossipol estão exibidos no gráfico da figura 3. Verifica-se que o hexano foi o solvente que extraiu o mais baixo teor dentre os ensaiados, o que corrobora com o raciocínio de que o perfil apolar acentuado desse solvente não conseguiu suplantar as interações do gossipol com a matriz proteica. As misturas de solventes, em geral, produziram micelas e óleos com resultados altos. A amostra I, que representa o material que foi previamente tratado antes da extração, apresentou resultados semelhantes ao da amostra crua, o que era esperado uma vez que o comportamento do solvente é o mesmo, variando mais sensivelmente em relação ao rendimento, como mostrado na figura 4.

O acetato de etila (amostra A) apresentou um dos mais acentuados valores de gossipol, demonstrando que a polaridade atribuída ao composto por seu grupamento carbonila ajudou a solubilizar a molécula de interesse. Se o resultado procurado fosse uma menor fixação do gossipol à torta, esse seria um solvente interessante. O ciclohexano destacou-se dos demais solventes por apresentar um valor mais próximo ao encontrado utilizando-se o hexano. Por se tratar também de um composto essencialmente apolar, associa-se esse efeito de solvência mais pronunciada no óleo do que no referido composto polifenólico. Como sua destilação ocorreu sem problemas relacionados à performance, acredita-se que é necessário um melhoramento em parâmetros da extração referentes a evolução no seu rendimento. Possivelmente, um tratamento no material a ser extraído pode aumentar esse rendimento, de forma análoga ao ocorrido na amostra I em relação à amostra A. A figura 4 compila as informações da tabela 2, de forma comparativa. Pode-se notar que em geral as amostras com maior rendimento apresentaram também uma maior quantidade de gossipol. Como já dito, essa é uma característica que seria bem explorada se o objetivo fosse a produção de torta "pobre" nesse componente. A amostra $\mathrm{G}$ (etanol puro) apresentou um resultado alto e um teor de gossipol relativamente menor que a média, portanto, uma possível e interessante alternativa. Uma ressalva deve ser levantada quanto ao comportamento da mistura na fase de destilação, como já citado, para a sua otimização há a necessidade de um estudo mais aprofundado das condições de sua operação. De modo geral, nenhum solvente ou mistura conseguiu se equiparar ao hexano, em termos de rendimento e de extração com teor reduzido de gossipol. Isso mostra que as porções fortemente polares dos solventes testados solubilizam de maneira efetiva o gossipol, o que é indesejado para a indústria de óleo. 


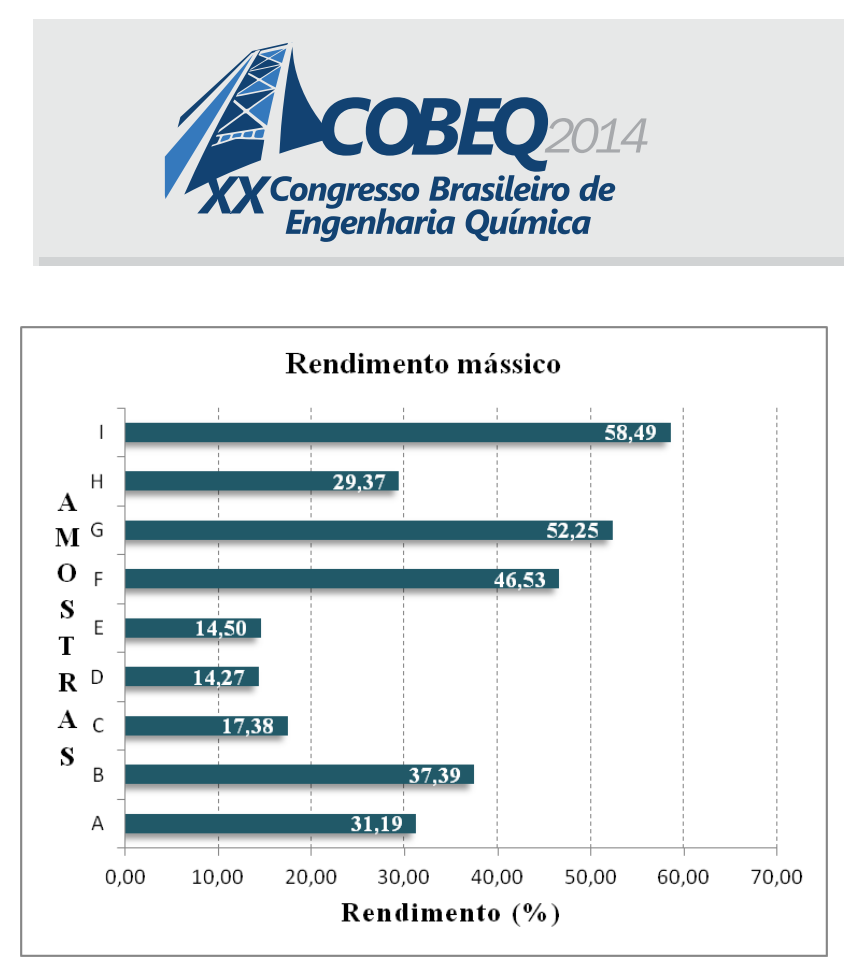

Figura 2 - Rendimento mássico

Fonte: $\mathrm{O}$ autor
19 a 22 de outubro de 2014

Florianópolis/SC

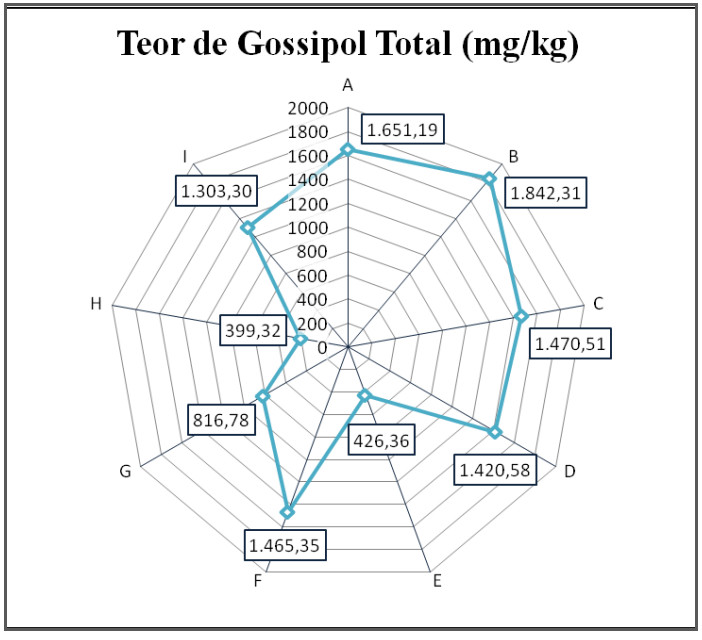

Figura 3 - Teor de Gossipol Total pela AOCS

Ca $13-56$

Fonte: $\mathrm{O}$ autor

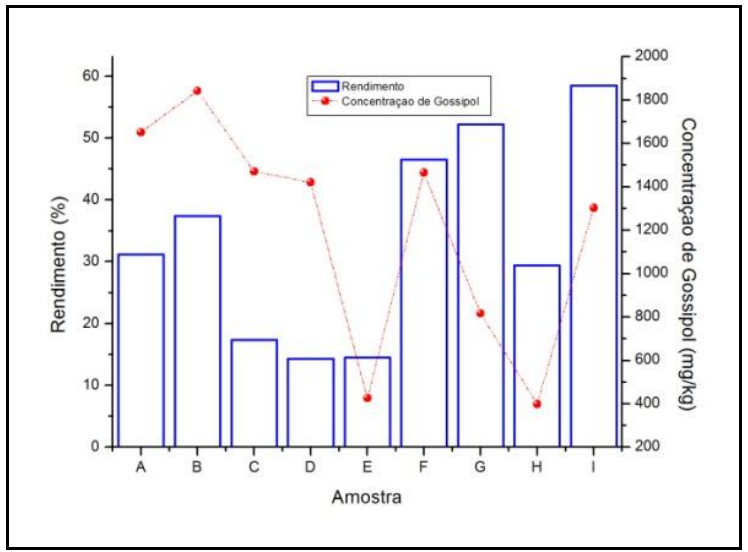

Figura 4 - Avaliação comparativa dos resultados Fonte: $\mathrm{O}$ autor

\section{CONSIDERAÇÕES FINAIS}

Com base nos resultados obtidos foi possível verificar o perfil de solvência do óleo nos solventes testados, tendo destaque o ciclohexano e sob certa perspectiva o etanol. Entretanto, faz-se necessária uma operação mais parametrizada e controlada para se obter um ponto ótimo de trabalho. Em termos de rendimento, o preparo das sementes aumentou sensivelmente o poder de extração. Conclui-se que a escolha de solvente alcançou parcialmente o preterido. Portanto, se as proporções desse solvente se tornassem majoritárias, poder-se-iam encontrar resultados mais próximos do que se deseja. 


\section{9 a 22 de outubro de 2014 \\ Florianópolis/SC}

\section{REFERÊNCIAS}

BECKER, W.Solvent extration of Soybeans. Journal of the American Oil Chemists' Societ, 55, 754761., 1978,apud. RODRIGUES, C. E. D. C. Utilização de solvente biorrenovável nos processos de extração e desacidificação de óleos vegetais, $172 \mathrm{f}$. Tese (Livre-docência em Equilibrio de Fases e Processos de Separação na Industria de Alimentos) - Departamento de Engenharia de Alimentos Faculdade de Zootecnia e Engenharia de Alimentos, Universidade de São Paulo, Pirassununga, SP, 2011.

JOHSON, L. A.; LUSAS, E. W. Comparision of Alternatives Solvents for Oils Extraction. Journal of American Oil Chemists Society, Texas, 60,1983. 229-242.

KARNOFSKY, G. The teory of solvent extration. Journal of the American Oil Chemists' Society, 26, 564-569, 1949, apud. RODRIGUES, C. E. D. C. Utilização de solvente biorrenovável nos processos de extração e desacidificação de óleos vegetais, $172 \mathrm{f}$. Tese (Livre-docência em Equilibrio de Fases e Processos de Separação na Industria de Alimentos) - Departamento de Engenharia de Alimentos Faculdade de Zootecnia e Engenharia de Alimentos, Universidade de São Paulo, Pirassununga, SP, 2011.

KEMPER, T. G. Oil Extraction. In: SHAHIDI, F. Bailey's Industrial Oil and Fat Products. sixth. ed. [S.1.]: John Wiley \& Sons, Inc., v. 6, 2005. Cap. 5.2, p. 57-98.

KENAR, J. A. Review: Reaction chemistry of Gossypol and Its Derivatives. Journal of the American Oil Chemits' Society, Illinois, 83, 4, 2006. 269-302.

MENESES, C. H. S. G. Qualidade fisiológica de sementes de algodão submetidas a estresse hídrico induzido por polietilenoglicol 6000, 97 p. Dissertação (Mestrado em Agronomia). Centro de Ciências Agrárias - Universidade Federal da Paraíba, Areia, PB, 2007.

O'BRIEN, R. D. et al. Cottonseed Oil. In: SHAHIDI, F. Bailey's Industrial Oil and Fat Products. Sixth. ed. [S.1.]: Jonh Wiley \& Sons, Inc., v. six, 2005. Cap. 2.5, p. 173-279.

PESCE, D. M. C. Efeitos da dieta contendo caroço de algodão no desempenho, caracteristicas quantitativas da carne de novilhos Nelore confinados., 138 f. Tese (Doutorado em Zootecnia Qualidade e Produtividade Animal), Pirassununga, SP, , 2008.

RODRIGUES, C. E. D. C. Utilização de solvente biorrenovável nos processos de extração e desacidificação de óleos vegetais, 172 f. Tese (Livre-docência em Equilibrio de Fases e Processos de Separação na Industria de Alimentos) - Departamento de Engenharia de Alimentos - Faculdade de Zootecnia e Engenharia de Alimentos, Universidade de São Paulo, Pirassununga, SP, 2011.

STIPANOVIC, R. D. et al. Total and Percent Atropisomers of Gosypol and Gossypol-6-methyl Ether in Seeds from Pima Cottos and Acessios of Gossypium Barbadense L. Journal of Agricultural and Food Chemistry, Texas, 57, 2009. 566-571.

WILLIAMS, M. A. Recovery of oils and fats from oilseeds and fatty materials. In: SHAHIDI, F. Bailey's Industrial Oil and Fat Products. sixth. ed. [S.1.]: John Wiley \& Sons, Inc., v. 6, 2005. Cap. 5.3, p. 99-189. 